\title{
Performance Evaluation of Alkali Activated Fly Ash Lightweight Aggregates
}

\author{
Gomathi Perumal ${ }^{\mathrm{a}}$ and Sivakumar Anandan ${ }^{\mathrm{b}}$ \\ Structural Engineering Division, VIT University, Vellore, Tamil Nadu, India \\ E-mail: agomathi.p@vit.ac.in, bsivakumara@vit.ac.in (Corresponding author)
}

\begin{abstract}
The potential use of fly ash obtained from thermal power plant for producing artificial lightweight aggregate has been systematically investigated in this study. Use of processed artificial aggregates from industrial wastes instead of natural aggregates can significantly reduce the cost of concrete production. Fly ash has been used in concrete either as supplementary cementitious material or as fine aggregate substitution. This study deals with the use of fly ash as aggregate by means of artificial production using pelletization process. The influence of alkali activator on the production and strength enhancement was studied. Also, the properties of alkali- activated aggregate using various binder materials such as cement, bentonite, metakaolin and blast furnace slag were studied. Moreover, the study emphasizes the efficient production of cold-bonded fly ash aggregate using cement, bentonite, furnace slag and metakaolin. Mechanical strength properties of various fly ash aggregate were tested for crushing strength and impact strength. The investigation results suggested that the cold-bonded fly ash lightweight aggregate using slag showed a highest crushing strength of $22.81 \mathrm{MPa}$ and also exhibited a lower water absorption of $13.01 \%$. The influence of binary blends of fly ash and a binder was observed to be an important parameter for achieving a high strength aggregate.
\end{abstract}

Keywords: Granulation, fly ash, bentonite, metakaolin, furnace slag, pelletization, crushing, impact.

ENGINEERING JOURNAL Volume 18 Issue 1

Received 13 March 2013

Accepted 3 June 2013

Published 14 January 2014

Online at http://www.engj.org/

DOI:10.4186/ej.2014.18.1.77 


\section{Introduction}

Prefabricated concrete elements are an important application which finds the potential use of lightweight aggregate. Light weight concrete produced using artificial aggregates are of great choice owing to high strength to weight ratio. Even though artificial lightweight aggregate are used in conventional concrete they offer some improved physical characteristics compared to the natural aggregate, including reduced self weight of structure, higher thermal resistance and superior sound-proof qualities. The use of lightweight aggregate concrete can reduce the self weight of the structures and dimensions of structural element. [1]. In recent years, studies have been carried out for the production of various types of cold-bonded fly ash aggregate. The natural lightweight aggregates available in north-eastern Jordan country were used to produce the high strength lightweight aggregate concrete. [2]. The advantages of producing artificial lightweight aggregate is that it does not deplete the natural resources and also to prevent the damages in the aggregate mining industries. [3]. The normal weight aggregate concrete is an uneconomical of using structural application as compared to the fly ash lightweight aggregate concrete. [4]. Granulation process is a common method to produce artificial aggregate. Manufacturing of artificial lightweight aggregate were produced by using various industrial by- products such as fly ash, furnace slag, clay material, incineration sludge ash etc. As there are only limited details on production techniques and parameters influencing properties of fly ash aggregates have been reported in the literature review and a systematic investigation is required in this direction. The application of LWAC was suggested for the use in marine structure, which gives better protection to a steel reinforcement against corrosion. Artificial lightweight aggregate is highly porous in nature as compared to the natural lightweight aggregate. The expanded clay lightweight aggregate showed water absorption around 6 to $7 \%$ for 24 hours. [5]. The disc pelletizer machine has higher efficiency for aggregate production as compared to that of drum pelletizer or cone pelletizer machine [6].

The present study focused on the production and testing of artificial lightweight aggregates produced from fly ash with the effect of binder addition. Also, the study aims at to evaluate the mechanical properties of various fly ash aggregates and to obtain a bulk density range between 882 to $1120 \mathrm{~kg} / \mathrm{m}^{3}$.

\section{Experimental Study}

\subsection{Materials Used}

The chemical and physical properties of various binder materials are given in Table 1. Class F Fly ash an industrial waste by product obtained from Ennore thermal power plant was used for producing aggregates. The effect of bonding was achieved in fly ash aggregate with the addition of binding agent such as cement (OPC 53 grade), furnaces slag, bentonite and metakaolin by the weight of fly ash. The alkali solution containing sodium hydroxide was mixed with the binder water for pelletization process.

Table 1. Chemical and physical properties of various binder materials used in this study.

\begin{tabular}{lccccc}
\hline Observation & Fly ash -class F & Cement & Furnace slag & Bentonite & Metakaolin \\
\hline Specific gravity & 2.1 & 3.13 & 2.86 & 2.64 & 2.52 \\
Blaine's fineness $\left(\mathrm{m}^{2} / \mathrm{kg}\right)$ & 400 & 325 & 400 & - & 800 \\
\hline \multicolumn{7}{r}{} & Chemical properties & & & & \\
\hline $\mathrm{SiO}_{2}$ & 56.2 & 18.5 & 32.3 & 47.84 & 41.4 \\
$\mathrm{Al}_{2} \mathrm{O}_{3}$ & 25.8 & 5.24 & 10.48 & 14.85 & 30.5 \\
$\mathrm{Fe}_{2} \mathrm{O}_{3}$ & 6.8 & 5.90 & - & 9.61 & 1.0 \\
$\mathrm{CaO}$ & 3.67 & 60.9 & 37.47 & 2.29 & 0.3 \\
$\mathrm{MgO}$ & 1.76 & 1.10 & 4.4 & 2.20 & 1.8 \\
$\mathrm{SO}_{3}$ & 0.47 & 1.50 & - & - & 0.9 \\
$\mathrm{Na}_{2} \mathrm{O}$ & 2.06 & - & - & 2.88 & 0.9 \\
$\mathrm{~K}_{2} \mathrm{O}$ & 0.01 & - & - & 1.45 & - \\
$\mathrm{Cl}$ & 0.52 & 0.002 & - & - & - \\
Loss on ignition & - & 0.80 & - & 19.73 & 18.16 \\
\hline
\end{tabular}




\subsection{Production of Aggregates}

Granulation technique by means of cold bonding process is a common method for production of artificial lightweight aggregate using a fabricated disc type pelletizer machine shown in Fig. 1. The pelletizer disc was fabricated for a diameter of the disc around $0.50 \mathrm{~m}$ and $0.27 \mathrm{~m}$ depth based on the design. The angle of the pelletizer can be adjusted from $35^{\circ}$ to $50^{\circ}$ with the speed of the drum adjusted between 40 to $55 \mathrm{rpm}$, In the present study, based on the initial studies conducted on the pelletization process the angle was set at $36^{\circ}$ and speed of $55 \mathrm{rpm}$, for achieving the maximum efficiency as well as desired size and shape of aggregates.

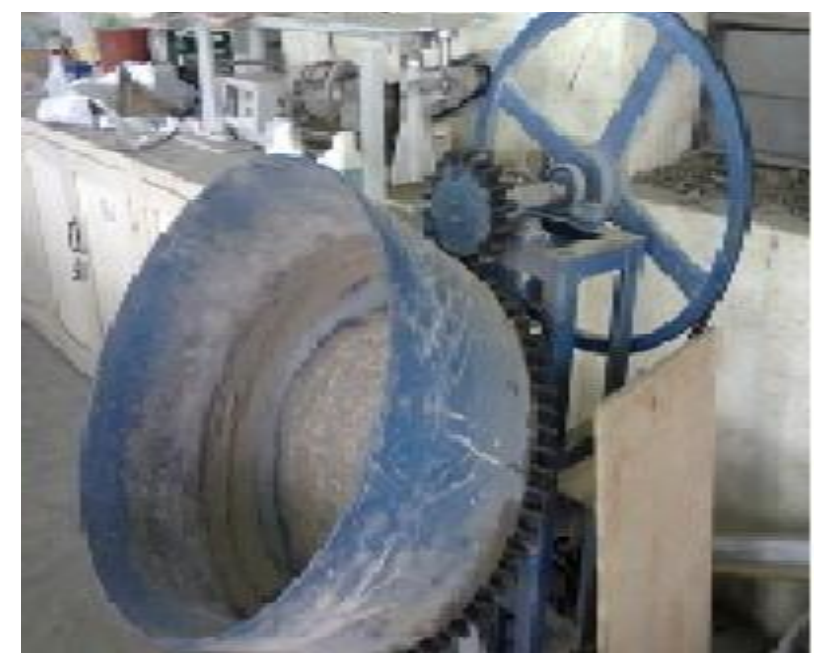

Fig. 1. Disc pelletizer machine.

Totally five different types of aggregates were produced for various binder and fly ash and the mix combination of each binder material is given in Table 2. Initially the fly ash and binder material were mixed homogenously in the pelletizer disc and then the calculated water is sprayed during pelletization operation. During this process, small seeds grow and the growth of seeds increases upon time duration. Finally, the discharge of pellets has been collected in the disc. After production, the aggregates were air dried and kept for subsequent hardening in hot air oven at temperature of $100^{\circ} \mathrm{C}$ up to 7 days as shown in Figs. 2 to 5.

Table 2. Mix proportions of various type of lightweight aggregates used in the study.

\begin{tabular}{lcccccccc}
\hline $\begin{array}{l}\text { Aggregate } \\
\text { type }\end{array}$ & $\begin{array}{c}\text { Duration } \\
\text { (minutes) }\end{array}$ & $\begin{array}{c}\text { Fly } \\
\text { ash } \\
\text { (gms) }\end{array}$ & $\begin{array}{c}\text { Furnace } \\
\text { slag } \\
\text { (gms) }\end{array}$ & $\begin{array}{c}\text { Metakaolin } \\
\text { (gms) }\end{array}$ & $\begin{array}{c}\text { Bentonite } \\
\text { (gms) }\end{array}$ & $\begin{array}{c}\text { Cement } \\
\text { (gms) }\end{array}$ & $\begin{array}{c}\text { NaOH } \\
\text { (gms) }\end{array}$ & $\begin{array}{c}\text { Water } \\
\text { content } \\
\text { (gms) }\end{array}$ \\
\hline F3 & 15 & 1000 & 0 & 0 & 0 & 0 & 120 & 250 \\
30G2 & 15 & 700 & 300 & 0 & 0 & 0 & 100 & 250 \\
30MT3 & 15 & 700 & 0 & 300 & 0 & 0 & 120 & 250 \\
20B2 & 15 & 800 & 0 & 0 & 200 & 0 & 100 & 250 \\
20C2 & 15 & 800 & 0 & 0 & 0 & 200 & 100 & 250 \\
\hline
\end{tabular}

Note: For $12 \mathrm{M}$ concentration, 120gms of sodium bydroxide added in $250 \mathrm{ml}$ of water; $10 \mathrm{M}$ concentration, $100 \mathrm{gms}$ of sodium bydroxide added in $250 \mathrm{ml}$ of water. 


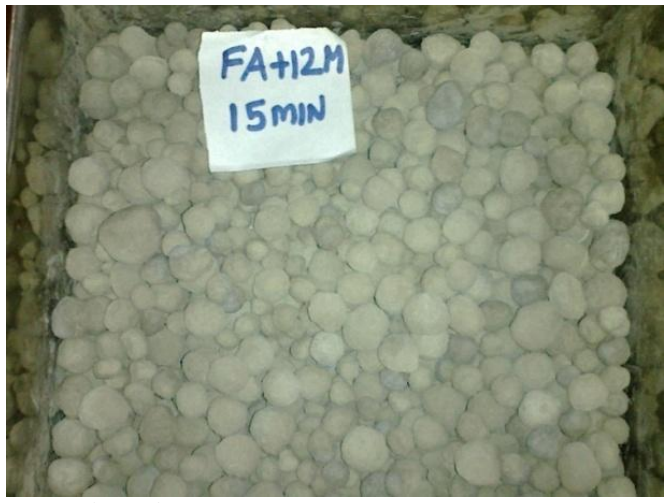

Fig. 2. Fly ash aggregate.

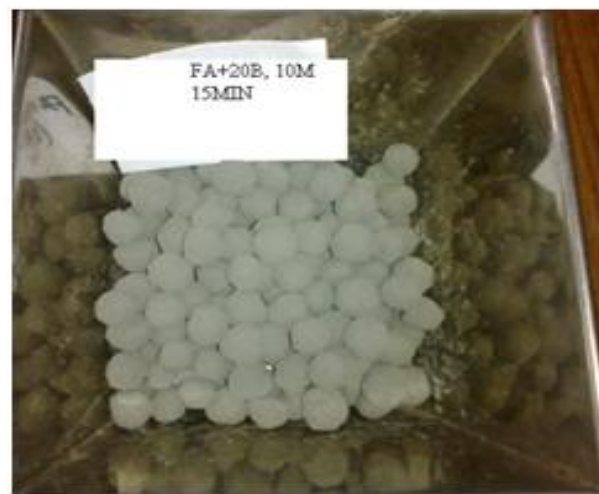

Fig. 4. Fly ash-bentonite aggregate.

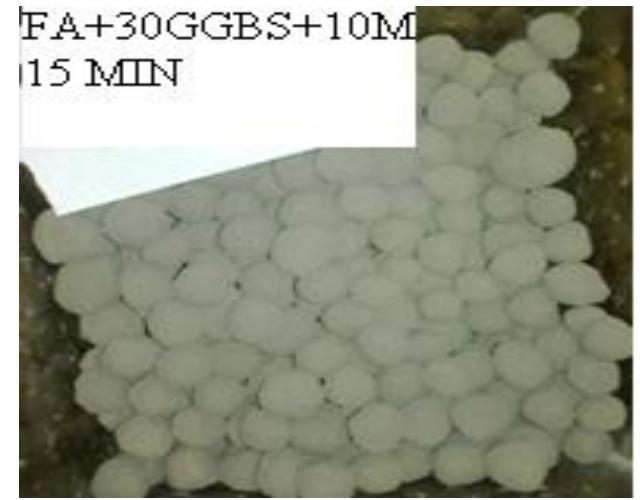

Fig. 3. Fly ash-furnace slag aggregate.

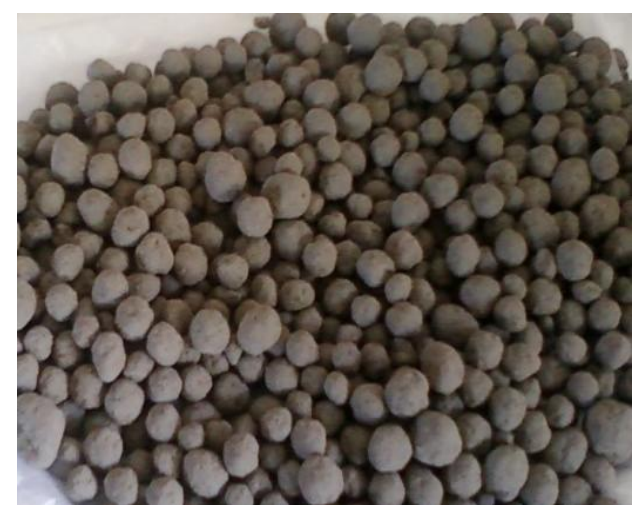

Fig. 5. Fly ash-metakaolin aggregate.

\subsection{Strength of Individual Fly Ash Aggregate}

Crushing strength of individual pellet was carried out in California bearing ratio (CBR) testing machine and the Fig. 6 shows the test set up for carrying out the test. A total of 30nos. of pellets have been collected from various sizes of aggregates and testing was performed for different types of aggregate. The individual crushing strength ' $\sigma$ ' was calculated from the formula given below.

$$
\sigma=\frac{2.8 \mathrm{P}}{\pi \mathrm{d}^{2}}
$$

where 'P' denotes the failure load and 'd' the diameter of pellet used for testing [7].

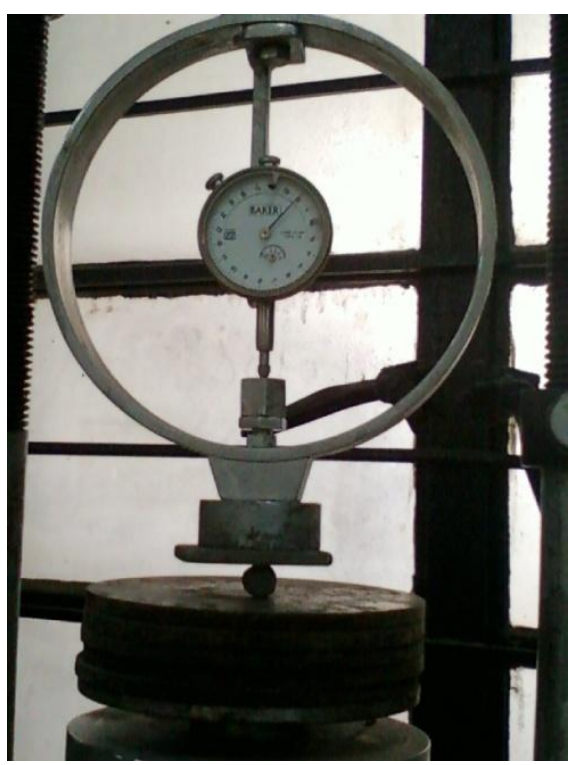

Fig. 6. Testing setup for individual crushing strength of pellet (CBR testing machine). 


\subsection{Aggregate Impact Values of Alkali Activated Fly Ash Aggregate}

The impact strength of the aggregates was tested using an impact testing machine as shown in Figs. 7 and 8. The impact value gives a relative measure of the resistance of an aggregate to repeated impact loading. The samples were tested for a hammer blow of 15 times dropping at a height of $350 \mathrm{~mm}$ and the material is then sieved in $2.36 \mathrm{~mm}$ according to standard specification (IS: 2386 (part IV) -1963) [8]. The impact value is defined as the ratio of weight of fines obtained to the total aggregate weight taken and is expressed in percentage as given below.

$$
\text { Aggregate impact value }=\frac{W_{2}}{W_{1}} \times 100
$$

where $W_{1}$ is the weight of the fly ash aggregate sample used for testing and $W_{2}$ is the weight of fraction passing through $2.36 \mathrm{~mm}$ sieve size.

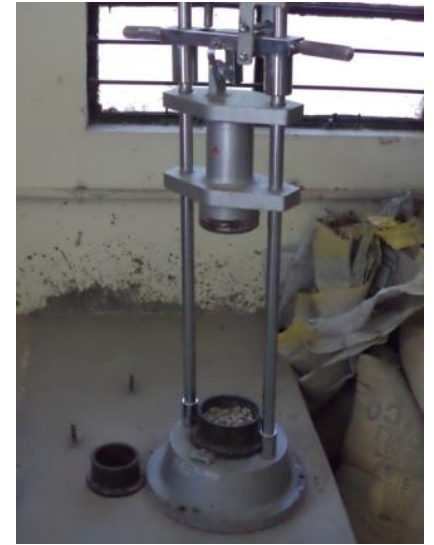

Fig. 7. Impact testing machine.

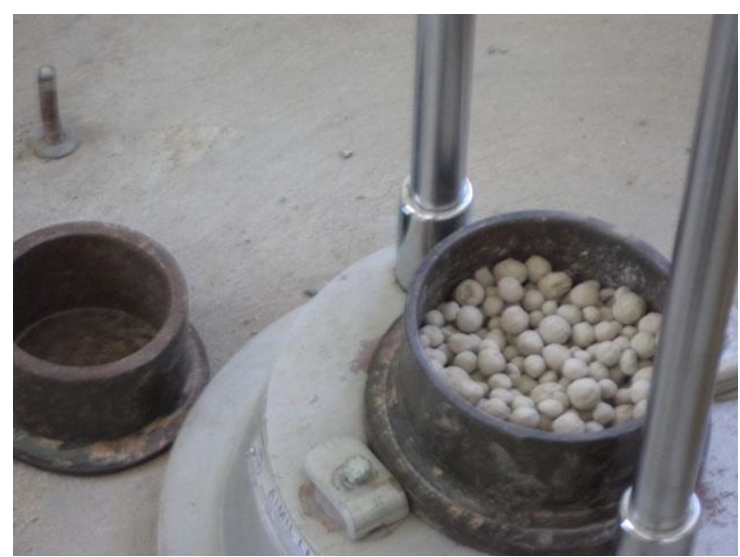

Fig. 8. Pelletized aggregate samples.

\section{Test Results and Discussion}

The light weight aggregate production depends on the efficiency of disc pelletization and the type of binder material added in the fly ash. Production efficiency of aggregates was calculated from the ratio of total weight of aggregates produced to that of total weight of fly ash added into the disc pelletizer. A good bonding efficiency and the stable formation of pellets were noticed with the addition of the binder material in the fly ash. The efficiency of pellets production was found to be higher when the slag is mixed with fly ash. The lightweight aggregate made with fly ash-slag binder showed the production efficiency of $99.07 \%$ compared to fly ash pellets which was around $66.95 \%$. In the case of fly ash-cement blended aggregate the efficiency was increased compared to bentonite and metakaolin binder in fly ash. The fly ash-bentonite aggregate showed higher efficiency than compared to fly ash-metakaolin aggregate. The physical properties of activated fly ash aggregate were given in Table 3 . The specific gravity of alkali activated fly ash aggregate without binder was found to have lower value as compared to activated fly ash aggregate with binder. The lowest specific gravity 1.75 was obtained for saturated surface dry aggregate as compared to fly ash cement and bentonite- fly ash aggregates which had specific gravity value of 1.98.

Table 3. Physical properties of various types of alkali activated fly ash aggregate.

\begin{tabular}{|c|c|c|c|c|c|c|}
\hline \multirow{2}{*}{$\begin{array}{l}\text { Aggregate } \\
\text { type }\end{array}$} & \multicolumn{2}{|c|}{ Specific gravity } & \multirow{2}{*}{$\begin{array}{c}\text { Water } \\
\text { absorption, (\%) }\end{array}$} & \multicolumn{2}{|c|}{$\begin{array}{l}\text { Bulk density, } \\
\left(\mathrm{kg} / \mathrm{m}^{3}\right)\end{array}$} & \multirow{2}{*}{$\begin{array}{c}\text { Efficiency, } \\
(\%)\end{array}$} \\
\hline & SSD & OD & & LBD & RBD & \\
\hline F3 & 1.75 & 1.44 & 21.26 & 978.34 & 1052.23 & 66.95 \\
\hline 30G2 & 1.98 & 1.75 & 13.01 & 983.44 & 1077.3 & 99.07 \\
\hline 30MT3 & 1.80 & 1.53 & 17.86 & 867.52 & 882.17 & 68.74 \\
\hline 20B2 & 1.84 & 1.58 & 16.39 & 966.88 & 1062.29 & 72.24 \\
\hline $20 \mathrm{C} 2$ & 1.98 & 1.67 & 18.75 & 1032.4 & 1120.06 & 79.00 \\
\hline
\end{tabular}

Note: SSD-saturated surface dry condition, OD-oven dry condition, LBD-loose bulk density, and RBD-rodded bulk density. 
The water absorption tests on aggregate reflect the porosity and found that porosity of the aggregate decreased with the addition of binder material in fly ash. It can be noted from the test results that the water absorption of fly ash aggregate showed $21.26 \%$ and was found to decrease by $13.01 \%$ with the furnace slag addition. Further, water absorption of $16.39 \%$ was noted for fly ash-bentonite aggregates and $17.86 \%$ for fly ash-metakaolin aggregates. It can be interpreted that the addition of binder in fly ash resulted in refined pore structure and hence resulted in reduction in water absorption. The addition of binder materials such as bentonite, metakaolin, furnace slag and cement can possibly lead to pore filling effect with fly ash particles. Thus can result in the effective packing of finer particles sizes and provides an improved micro-structural development during aggregate production.

The crushing strength and impact strength test results for various lightweight aggregates are given in Table 4. Strength improvement was noticed with the binder addition and a maximum strength of $16 \mathrm{MPa}$ was obtained for smaller size of pellet (6 mm diameter) compared to $7.83 \mathrm{MPa}$ for bigger size of $(16 \mathrm{~mm}$ diameter) fly ash slag aggregate $\left(30 \mathrm{G}_{2}\right)$ (as shown in Figs. 9 and 10). The strength of pellet was tested at various days of curing as shown in Figs. 11 to 13. It can be noted that among the different types of aggregates produced in this study, a highest crushing strength value of $22.81 \mathrm{MPa}$ was obtained in the case of fly ash-furnace slag based aggregate $\left(30 \mathrm{G}_{2}\right)$. Whereas, in the case of fly ash-metakaolin $\left(30 \mathrm{MT}_{3}\right)$ and fly ash-bentonite $\left(20 \mathrm{~B}_{2}\right)$ aggregate a maximum crushing strength value of $17.62 \mathrm{MPa}$ and $14.51 \mathrm{MPa}$ was obtained respectively. Also, the impact value for lightweight aggregate consisting slag-fly ash mixes showed lower crushing value compared to various binder material in fly ash aggregate and satisfies the structural requirement as per IS: 2386 (part IV) -1963 [8]. In general of all the lightweight aggregates tested the fly ash-slag blended mixes exhibited excellent mechanical properties in terms of crushing strength and impact strength. Also, the water absorption test results of fly ash -slag binder exhibited lowest value of $13.01 \%$.

It can be concluded from the experimental results that, the strength of aggregate produced by means of pelletization was dependent on the addition of binder materials along with fly ash. This improved the bonding properties as well as contributed for the well development of micro-structure. Also, the fineness of binders had shown significant degree of closer packing of particles leading to higher efficiency in terms of strength as well as water tightness. Cold-bonded aggregates produced in this study were found to be satisfactory in terms of strength owing to their high bonding efficiency due to inter-particle bonding (surface adhesion). It is also justified that, when the binder particles are finer the specific surface area increases and can provide closer packing of intergranular particles. Also, the addition of alkali activator (sodium hydroxide) along with mix water initiates the geo-polymerization reaction between silica and alumina present in the binder materials leading to the formation of polysialate polymer compound. This provides faster hardening of cold bonded aggregates and gives early age strength gain properties of aggregates. In general, it can be also summarized that the various geo-polymer based aggregates produced in this study provides a reasonable strength attainment meeting the performance requirements of light weight aggregate. 
Table 4. Mechanical properties of various types of fly ash lightweight aggregate.

\begin{tabular}{|c|c|c|c|c|c|c|c|c|c|}
\hline \multirow{2}{*}{$\begin{array}{l}\text { Aggregate } \\
\text { type }\end{array}$} & \multirow{2}{*}{$\begin{array}{l}\text { Age of } \\
\text { testing } \\
\text { (days) }\end{array}$} & \multicolumn{5}{|c|}{ Crushing strength of individual pellets } & \multirow{2}{*}{$\begin{array}{c}(\mathrm{MPa}) \\
16 \\
\mathrm{~mm} \\
\end{array}$} & \multicolumn{2}{|c|}{ Impact value $(\%)$} \\
\hline & & $6 \mathrm{~mm}$ & $\begin{array}{c}8 \\
\mathrm{~mm}\end{array}$ & $\begin{array}{c}10 \\
\mathrm{~mm}\end{array}$ & $\begin{array}{c}12 \\
\mathrm{~mm}\end{array}$ & $\begin{array}{c}14 \\
\mathrm{~mm}\end{array}$ & & $\begin{array}{l}\text { Experimental } \\
\text { value }\end{array}$ & Remarks \\
\hline \multirow[t]{2}{*}{$\mathrm{F}_{3}$} & 1 & - & - & - & 8.52 & 7.65 & 6.36 & \multirow[t]{2}{*}{50.47} & \\
\hline & 7 & - & - & - & 9.5 & 8.98 & 7.8 & & Satisfactory \\
\hline \multirow{2}{*}{$30 \mathrm{G}_{2}$} & 1 & 16.00 & 15.16 & 13.7 & 12.35 & 12.2 & 7.83 & \multirow{2}{*}{31.96} & $\begin{array}{l}\text { as per IS: } \\
2386 \text { (part }\end{array}$ \\
\hline & 7 & 22.81 & 18.85 & 14.89 & 13.98 & 12.81 & 12.80 & & $\begin{array}{l}\text { IV) }-1963 \text {, the } \\
\text { impact value } \\
\text { does not }\end{array}$ \\
\hline \multirow[t]{2}{*}{$30 \mathrm{MT}_{3}$} & 1 & 10.02 & 7.09 & 5.47 & - & - & - & \multirow[t]{2}{*}{38} & exceed $45 \%$ \\
\hline & 7 & 17.62 & 10.03 & 7.81 & - & - & - & & $\begin{array}{l}\text { by weight of } \\
\text { aggregate }\end{array}$ \\
\hline \multirow{2}{*}{$20 \mathrm{~B}_{2}$} & 1 & 9.59 & 7.09 & 6.99 & 3.43 & - & - & \multirow{2}{*}{35} & used in \\
\hline & 7 & 14.51 & 10.22 & 8.67 & 6.57 & - & - & & $\begin{array}{l}\text { structural } \\
\text { concrete. }\end{array}$ \\
\hline \multirow{2}{*}{$20 \mathrm{C}_{2}$} & 1 & - & - & 4.98 & 4.9 & 4.8 & - & \multirow{2}{*}{36} & \\
\hline & 7 & - & - & 7.64 & 7.02 & 6.98 & - & & \\
\hline
\end{tabular}

Note: "-" denotes particular size of aggregate not available.

Standard deviation of crushing strength value of aggregates (30 nos.) was below $7.02 \%$.

Standard deviation of Impact strength value of aggregates (30 nos.) was below $9.25 \%$.

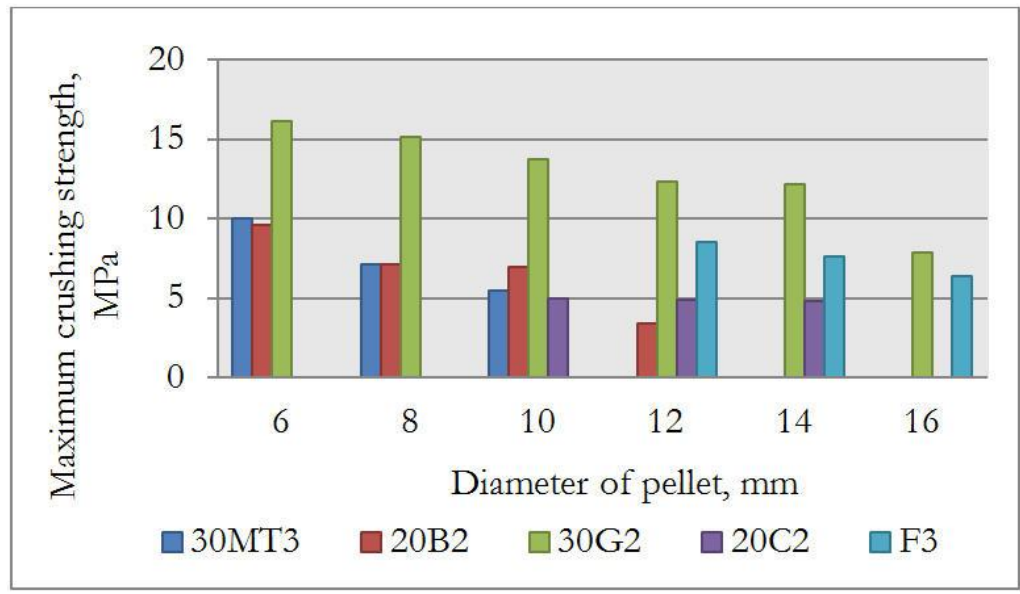

Fig. 9. Crushing strength of various sizes of fly ash lightweight aggregate for 1 day curing. 


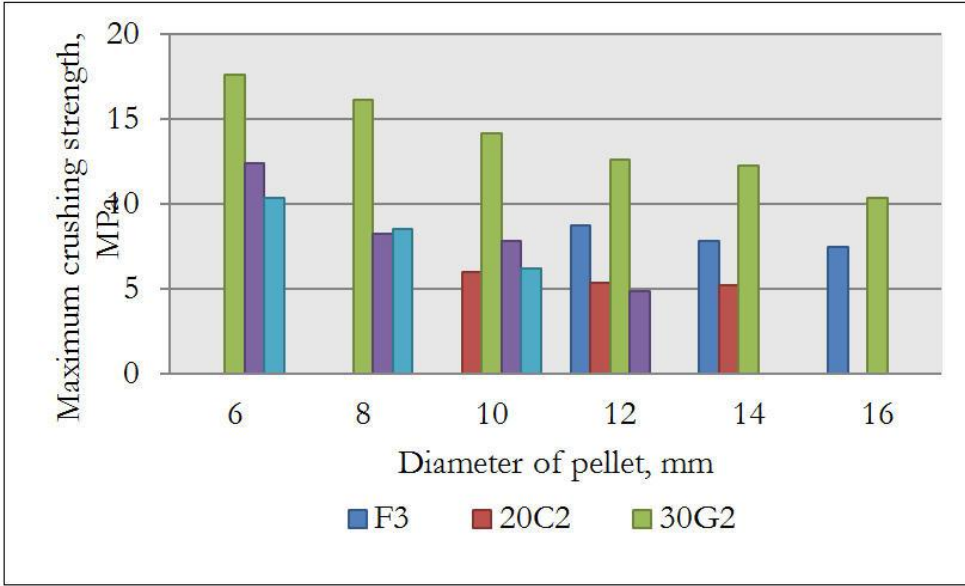

Fig. 10. Crushing strength of various sizes of fly ash lightweight aggregate for 3 days curing.

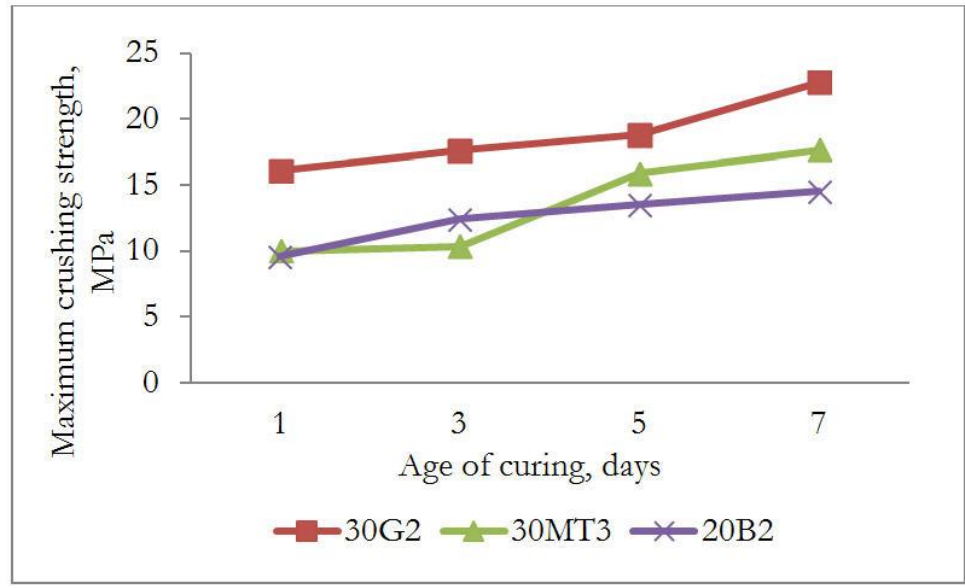

Fig. 11. Crushing strength of individual aggregate of $6 \mathrm{~mm}$ diameter for various curing days.

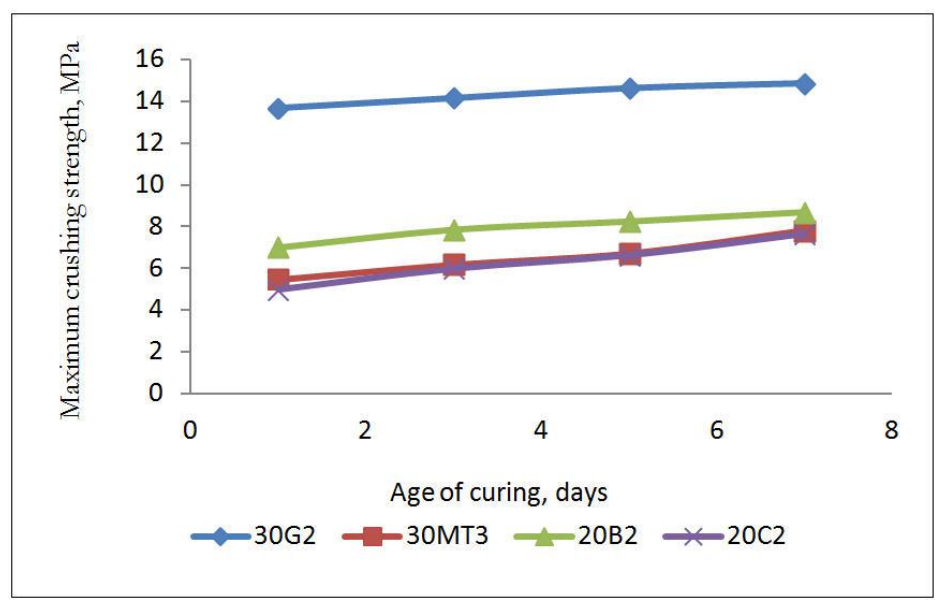

Fig. 12. Crushing strength of individual aggregate of $10 \mathrm{~mm}$ diameter for various curing days. 


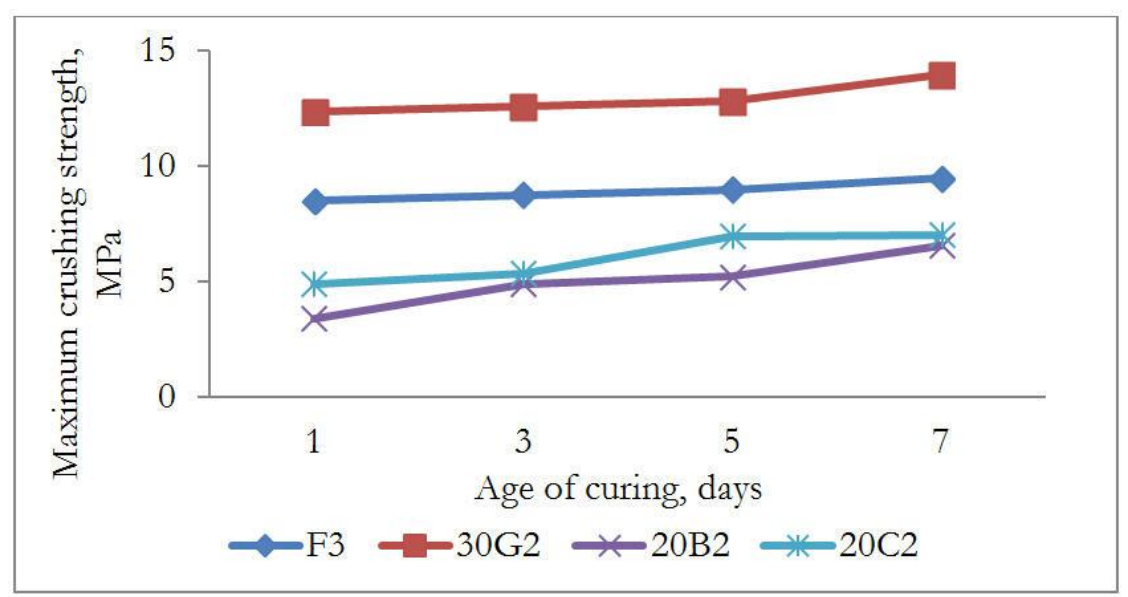

Fig. 13. Crushing strength of individual aggregate of $12 \mathrm{~mm}$ diameter for various curing days.

\section{Conclusions}

Investigation on the various cold-bonded fly ash based aggregate revealed the following significant findings.

- Pelletization efficiency was found to be increased with the addition of binder as it synergizes the bonding effect of fly ash during agglomeration.

- The efficiency of lightweight aggregate made with fly ash-slag binder showed $99.07 \%$ as compared to other fly ash based aggregates.

- Crushing strength was increased with the addition of binder and showed a maximum strength of $22.81 \mathrm{MPa}$ in the case of fly ash- slag based aggregate.

- Lowest impact strength value of $31.96 \%$ was obtained for fly ash-furnace slag based aggregate and was better compared to other type of aggregates.

- The lowest water absorption of $13.01 \%$ was obtained in the case of fly ash-furnace slag aggregate as compared to other types fly ash based aggregates.

- The experimental results also showed that a lowest bulk density of $882 \mathrm{~kg} / \mathrm{m}^{3}$ can be obtained in the case of fly ash-metakaolin aggregate (30MT3) and a highest bulk density of $1120 \mathrm{~kg} / \mathrm{m}^{3}$ (20C2) can be obtained in fly ash-cement aggregates using pelletization process.

- It can be summarized from the various characterization studies conducted on flyash lightweight aggregates that, the fly ash-furnace slag lightweight aggregates exhibited satisfactory performance

\section{References}

[1] K. S. Chia and M.-H. Zhang, "Water permeability and chloride penetrability of high-strength lightweight aggregate concrete," Cement and Concrete Research, vol. 32, pp. 639-645, 2002.

[2] M. Smadi and E. Migdady, "Properties of high strength tiff lightweight aggregate concrete," Cement and Concrete Composites, vol. 13, pp. 129-135, 1991.

[3] O. Kayali, "Fly ash lightweight aggregates in high performance concrete," Constr Build Mater, vol. 22, pp. 2393-2399, 2008.

[4] S. Shanmugasundaram, S. Jayanthi, R. Sundararajan, C. Umarani, and K. Jagadeesan, "Study on utilization of fly ash aggregates in concrete," Modern Applied Science, vol. 4, no. 5, pp. 44-57, 2010.

[5] J. R. Rossignolo and M. V. C. Agnesini, "Durability of polymer-modified lightweight aggregate concrete," Cement and Concrete Composites, vol. 26, pp. 375-380, 2004.

[6] J. M. J. M. Bijen, "Manufacturing processes of artificial lightweight aggregates from fly ash," International Journal of Cement Composites and Lightweight Concrete, vol. 8, no. 3, pp. 191-199, 1986.

[7] U. K. Niyazi and O. Turan, "Effects of lightweight fly ash aggregate properties on the behavior of lightweight concretes," Journal of Hazardous Materials, vol. 179, pp. 954-965, 2010.

[8] Method of Test For Aggregates For Concrete Part IV Mechanical Properties, Indian Standard IS: 2386 (part IV)1963. 
